\title{
Nanoparticles as Carrier for Improve Therapeutic Efficacy of Pioglitazone in Ocular Inflammatory Disorders: Development and Validation of a High Throughput HPLC-MS/MS Method for Its Quantitation in Ocular Tissues ${ }^{+}$
}

\author{
Esther Miralles-Cardiel 1,2,*, Marcelle Silva-Abreu ${ }^{3,4}$, Ana Cristina Calpena-Capmany ${ }^{3,4, *}$ and \\ Isidre Casals-Ribes ${ }^{1}$ \\ 1 CCiTUB (Scientific and Technological Centers), University of Barcelona, 08028 Barcelona, Spain; \\ isidre@ccit.ub.edu \\ 2 Department of Analytical Chemistry, Faculty of Chemistry, University of Barcelona, 08028 Barcelona, \\ Spain \\ 3 Department of Pharmacy, Pharmaceutical Technology and Physical Chemistry, Faculty of Pharmacy and \\ Food Sciences, University of Barcelona, 08028 Barcelona, Spain; silvadesabreu@ub.edu \\ 4 Institute of Nanoscience and nanotechnology (IN2UB), Faculty of Pharmacy and Food Sciences, University \\ of Barcelona, 08028 Barcelona, Spain \\ * Correspondence: emiralles@ub.edu (E.M.-C.); anacalpena@ub.edu (A.C.C.-C.); Tel.: +34-93-403-4652 (E.M.- \\ C.); +34-93-402-4578 (A.C.C.-C.) \\ + Presented at the 1st International Electronic Conference on Pharmaceutics, 1-15 December 2020; Available \\ online: https://iecp2020.sciforum.net/.
}

Received: date; Accepted: date; Published: date

\begin{abstract}
Pioglitazone is an oral anti-hyperglycemic agent and it is used for the treatment of diabetes mellitus type 2. The anti-inflammatory activity has also been demonstrated in the literature. Pioglitazone belongs to Class II of Biopharmaceutical Classification System, i.e., slightly soluble and highly permeable. Polymeric nanoparticle formulations play an important role in the improvement of the efficacy of ocular therapies. These systems are non-toxic and biodegradable, show appropriate physicochemical characteristics as well as prolonged release profile suitable for ocular delivery. An accurate, sensitive, selective, reproducible and high throughput HPLC-MS/MS method was validated to quantitate pioglitazone in ocular tissues (cornea, sclera, lens, aqueous humour and vitreous humour). The chromatographic separation was achieved in $10 \mathrm{~min}$ on a Kinetex C18 column. Linear response of pioglitazone was observed over the range of 5-100 ng/mL. The limit of quantitation was $10 \mathrm{ng} / \mathrm{mL}$ (in extract). The recovery of pioglitazone or pioglitazone encapsulated in nanoparticles of polylactic-co-glycolic acid-polyethylene glycol (PLGA-PEG) was in the range 85$110 \%$ in all tissues and levels tested. The intra-day and inter-day precision were $<5 \%$ and $<10 \%$ respectively. The obtained extracts demonstrated to be stable under various experimental conditions in all the studied matrices. This method can be applied to in vivo and ex vivo biodistribution studies related to the ocular administration of pioglitazone nanoparticles.
\end{abstract}

Keywords: pioglitazone (PGZ); PLGA-PEG; nanoparticles (NPs); ocular; HPLC-MS/MS 


\section{Introduction}

Pioglitazone (PGZ) is a hypoglycemic therapeutic drug used in the treatment of type 2 diabetes. Chemically belongs to the class of thiazolidinediones and according to the Biopharmaceutical Classification System (BCS) falls into Class II, i.e., slightly soluble and highly permeable. This drug is an agonist of the peroxisome proliferator-activated receptor (PPAR $\gamma$ ) which has reported functions as anti-inflammatory [1]. Studies have proven effects on inflammatory ocular processes [2-4], skin $[5,6]$, heart [7,8] or Azlheimer [9,10].

In ocular therapies one of the challenges is the effective penetration of the drugs through the eye's tissue barriers (e.g., corneal, sclera and conjunctiva) to reach targets and to sustain it. Normally, when ophthalmic formulations are used, less than $5 \%$ of the drug permeates the cornea which means that it is necessary to instill frequently. One of the most successful approaches to overcome this inconvenient is the use of colloidal suspensions of nanoparticles (NPs) as delivery systems [11,12]. These systems have been described in the literature showing the effectiveness for ocular delivery in form of liposomes and polymeric nanoparticles [2,13-15].

Polylactic-co-glycolic acid (PLGA) is one of the most studied synthetic polymers due to its biocompatibility and biodegradability. PLGA is approved by the US Food and Drug Administration (FDA) and the European Medicine Agency (EMA) for drug delivery systems in humans [16]. This polymer allows to develop very small particles with narrow polydispersity, therefore PLGA has been chosen to design NPs in biomedical applications such as vaccination, cancer, inflammation and other diseases. The advantage of the PEGylated polymer PLGA-PEG is that the hydrophobicity of the polymer decreases, thus increasing the stability and solutiliby in aqueous media and avoiding aggregation. Moreover PEG is biocompatible and approved polymer by the FDA for its use in humans.

In recent years some studies of our research group have been focused on pioglitazone nanoparticles of PLGA-PEG. These nanosystems have been optimized and characterized, and their anti-inflammatory activity as well as the tolerance have been proven [2].

The objective of this research was to develop and validate an HPLC-MS/MS method following the guidelines of the European Medicines Agency (2019) and U.S. Food and Drug Administration (2018) for bioanalytical methods validation $[17,18]$ to focus the analysis on the application of PGZNPs in the eye via an in vivo model for its use in inflammatory processes.

\section{Experiments}

\subsection{Chemicals and Reagents}

PGZ was purchased from Capot Chemical (Hangzhou, China) and diblock copolymer PLGAPEG 5\% (50:50) Resomer $^{\circledR}$ was obtained from Evonik Corporation (Birmingham, AL, USA). Poly(vinyl alcohol) Mw 30,000-70,000, 87-90\% hydrolyzed; dimethylsulfoxide (DMSO) and formic acid were acquired from Sigma-Aldrich-Merck (Darmstadt, Germany). Acetone, high-performance liquid chromatography (HPLC) gradient-grade acetonitrile and methanol were purchased from ITW Reagents (Barcelona, Spain). All reagents and solvents were analytical or HPLC-gradient grade. Ultrapure water (HPLC grade, $>18 \mathrm{M} \Omega \mathrm{cm}$ at $25^{\circ} \mathrm{C}$ ) was obtained by means of a Milli-Q apparatus from Millipore (Milford, MA, USA).

\subsection{Chromatographic Conditions}

The analysis were carried out using an Agilent 1260 liquid chromatograph (Agilent Technologies, Santa Clara, CA, USA). A reversed-phase Kinetex C18 column ( $2.6 \mu \mathrm{m}$ particle size, 50 $\times 2.1 \mathrm{~mm}$ ) from Phenomenex was used to perform the chromatographic separation. The gradient between formic acid $0.1 \%$ in water (A) and formic acid $0.1 \%$ in acetonitrile (B) was the following: $(\mathrm{t}(\mathrm{min}), \% \mathrm{~B}),(0,10),(4,74),(4.5,90),(6,90),(6.1,10),(10,10)$. The column temperature was maintained at $35{ }^{\circ} \mathrm{C}$. The optimization of mobile phases and column selection was based on suitability for mass 
detector, effect on sensitivity of the method and total time required for the analysis. The flow rate was fixed at $0.6 \mathrm{~mL} / \mathrm{min}$ and the injection volume at $1 \mu \mathrm{L}$.

The quantitation of PGZ was achieved using a triple quadrupole mass spectrometer 4000 QTRAP (AB Sciex Instruments, Concord, ON, Canada). Sensitivity was found to be maximum in positive ion mode, when turboionspray interface temperature and ion spray voltage were set at 550 ${ }^{\circ} \mathrm{C}$ and $5500 \mathrm{~V}$, respectively. Ion source gas 1 and ion source gas 2, nebulizer gas and auxillary gas respectively, were set at 50 and 30 respectively in an arbitrary scale. The curtain gas and collision gas were set at 25 and medium respectively in an arbitrary scale. The optimized compound parameters were the following: declustering potential (DP) 100, entrance potential (EP) 10, collision energy (CE) 35 and collision cell exit potential (CXP) 12.

The use of a triple quadrupole mass spectrometer allowed us to work in multiple reaction monitoring (MRM) mode. The $\mathrm{m} / \mathrm{z}$ transition pairs used for quantitation of PGZ (precursor ion/product ion) were 357.2/134.1 (most sensitive), and 357.2/119.1 for confirmation. The quadrupoles were set at unit resolution. The analytical data were processed with the Analyst software (version 1.6.2).

\subsection{Preparation of Standards, PGZ-NPs and Working Solutions}

\subsubsection{PGZ Standards}

A stock solution of $1 \mathrm{mg} / \mathrm{mL}$ of PGZ was prepared in methanol for subsequent intermediate, spiking and working standard solutions preparation in methanol. The calibration curve was prepared at concentrations of 5, 10, 25, 50, 75 and $100 \mathrm{ng} / \mathrm{mL}$ in methanol. Glass vials were used to store the solutions at $-20^{\circ} \mathrm{C}$. Spiking solutions in methanol were also prepared.

\subsubsection{Preparation of PGZ-NPs}

PGZ-NPs were obtained by the solvent displacement method described by Fessi et al., [19]. This technique consists of dissolving the polymer and the compound in an organic solvent, being a successful method to deliver the lipophilic drug. This technique is based on two phases: the organic and the aqueous phase. A total of $10 \mathrm{mg}$ of PGZ were previously solubilized in $0.5 \mathrm{~mL}$ DMSO. Moreover, $90 \mathrm{mg}$ of PLGA-PEG were dissolved with $5 \mathrm{~mL}$ of acetone and both organic solutions were mixed together followed by sonication in an ultrasonic bath $(100 \mathrm{w})$ for two minutes. This organic phase was added dropwise gently mixing, into $10 \mathrm{~mL}$ of an aqueous solution of PVA $2.5 \%, \mathrm{pH}=4.5$ (adjusted with $\mathrm{HCl} 0.1 \mathrm{M}$ ). The NPs dispersion was concentrated to $10 \mathrm{~mL}$ under reduced pressure (Vacuubrand PC 2001 Vario, Wertheim, Germany). The PGZ-NPs are stable in the fridge for several weeks.

\subsubsection{PGZ-NPs Working Solutions}

The suspension of PGZ-NPs was diluted 1/20 in water for spiking the tissues. Further, this solution was diluted in methanol to quantify the amount of PGZ. The chromatographic conditions for PGZ quantitation where adapted from previous studies [5].

\subsection{Biological Material}

Ocular specimens were obtained under veterinary supervision from pigs used in surgical university practices, according to the Ethics Committee of Animals Experimentation at the University of Barcelona. After chirurgical experimentation, the animals were euthanized and the eyes were immediately enucleated and transported to the laboratory in dry ice. Cornea, sclera, lens, aqueous humour and vitreous humour were excised in the laboratory and kept frozen at $-20^{\circ} \mathrm{C}$.

\subsection{Extraction Procedure}

Lens, aqueous and vitreous humour were vortex-mixed previously. Sclera and cornea were minced and thoroughly perforated using a needle to help the penetration of the extraction solution.

For cornea, sclera and lens, the taken weight was about $125 \mathrm{mg}$; for aqueous and vitreous humour the weight was about $250 \mathrm{mg}$. The samples were weighed into amber glass vials and were 
extracted in $2 \mathrm{~mL}$ of methanol using an ultrasonic bath during $30 \mathrm{~min}$. The solution was centrifuged at 10,000 rpm for $10 \mathrm{~min}$ at room temperature. The resultant supernatants were filtered through nylon filters of $0.22 \mu \mathrm{m}$ and injected into the HPLC-MS/MS system. The stability of the extracts showed that the supernatants could be collected and stored at $-20^{\circ} \mathrm{C}$ until use ( 3 months proven).

\subsection{Method Validation}

The method was validated according to the bioanalytical method validation guidelines of the EMA and the FDA and considering the acceptance criteria recommended for the following validation parameters: selectivity-specificity, matrix effect, calibration curve (response function), limits of quantification and detection, accuracy, precision, recovery, carry-over, dilution integrity and stability $[17,18]$.

\subsubsection{Selectivity and Specificity. Matrix Effect}

Blank tissues were analysed to determine the selectivity and specificity of the method. Any interference form unwanted tissue components at the elution time of PGZ was evaluated. The effect of tissue components on the ionization of PGZ was determined by comparison of the response of a PGZ standard in methanol and PGZ standard prepared in the blank extracts of each tissue. Along the validation procedure, the matrix effect was also evaluated with accuracy and precision data.

\subsubsection{Recovery}

Weighed tissues were spiked with PGZ at three levels of concentration in order to achieve the final concentrations in extract of about 10 (low), 20 (medium) and 100 (high) ng/mL, n = 3 each level. As PGZ was spiked from small volumes $(\mu \mathrm{L})$ of standard solutions prepared in methanol, in order to reduce pipetting errors, the aliquot added was weighed with minimum precision of $0.1 \mathrm{mg}$. Samples spiked with PGZ standard solution were extracted after $60 \mathrm{~min}$ waiting time at room temperature and those spiked with PGZ-NPs were extracted after $3 \mathrm{~h}$ waiting time at room temperature in order to left them interact with the tissue and better simulate incurred residues. The extracts were kept at $-20^{\circ} \mathrm{C}$ until HPLC-MS/MS analysis.

\subsubsection{Sample Dilution}

The sample dilution effect was also evaluated in order to ensure that PGZ concentrations beyond the upper limit of concentration of the calibration range could be correctly determined after dilution of the extract with methanol. Three replicates of spiked tissues were used to investigate the intra-day precision and accuracy of a 50-fold sample dilution. The tissues were spiked to achieve final concentration of PGZ in extract of about $50 \mathrm{ng} / \mathrm{mL}$.

\subsubsection{Calibration Curve}

The calibration curve was prepared using six calibration standards defined in Section 2.3. The chromatographic area of PGZ against the concentration of the calibration standards was plotted to construct the calibration curve. The linearity of the method was evaluated by weighted linear regression analysis, with $1 / \mathrm{x}^{2}$ as the weighting factor, using the least squares method [20]. The acceptance criteria for the back-calculated standard concentration was $\pm 15 \%$ deviation from the theoretical value. First, each calibration standard was analysed in replicate, in which case data from all replicates was used in the regression analysis. There was no significant difference between replicates, indicating that calibration standards could be single injected to construct the calibration curve. The calibration curve (6 standards) was prepared using freshly standards in each assessment.

\subsubsection{Accuracy and Precision}

The spiked levels of concentration corresponded to approximately 160, 320 and $1600 \mu \mathrm{g} / \mathrm{kg}$ for lens, cornea and sclera. In the case of aqueous humour and vitreous humour, the spiked levels of 
concentration corresponded to approximately 80,160 and $800 \mu \mathrm{g} / \mathrm{kg}$. The closeness of mean results determined by the method to the spiked concentration of the analyte and the repeatability was evaluated in terms of recovery. Three sets of three different levels were prepared and quantified on three separate days to determine the inter-day and intra-day precision and the accuracy of the method. Moreover, samples spiked with PGZ-NPs were also prepared and quantified for accuracy and intra-day precision $(n=3)$ at the three levels of concentration.

The acceptance criteria of the data included as the accuracy should be within $\pm 15 \%$ (recovery 85 $115 \%$ ). For limit of quantitation (LOQ), accuracy acceptable limit of deviation was $\pm 20 \%$ (recovery 80 $120 \%$ ). The precision around the theoretical value should not cross $15 \%$ of the CV. The acceptance criteria for precision and accuracy were defined as $C V \leq 15 \%$ and bias within $\pm 15 \%$, respectively $[17,18]$.

\subsubsection{Stability Experiments}

The obtained extracts from the recovery and precision study were kept at $-20{ }^{\circ} \mathrm{C}$ till the day of the HPLC-MS/MS analysis because of the availability of the equipment. The long-term stability evaluation was deduced from the obtained results of precision studies (reproducibility, three different days). One of the sets was injected after 3 months of the extraction, the other two sets after 9 and 15 days respectively.

Extracts of each tissue spiked approximately at the medium level of concentration were injected to determine the stability of the analyte in various predetermined conditions. The post-preparative stability of the samples was determined after comparison of the response of immediate injection of the extracted samples to that of the re-injected samples after keeping them in the refrigerated autosampler for $24 \mathrm{~h}$. The post-preparative stability of the drug was assessed taking into account the time that the samples could remain in queue in the chromatograph and, eventually, any failure of the chromatograph in a $24 \mathrm{~h}$ period. Short-term stability was determined after placing the extracts for 8 $\mathrm{h}$ on the bench top at room temperature. The time period for short-term stability study was determined based on the possible time spent for a batch sample analysis. The relative stability was calculated by considering the initial area of PGZ as $100 \%$.

\subsection{Bioavailability Experiment: In Vivo}

In order to investigate the ocular bioavailability and disposition of PGZ, pig eyes were treated with topical administration of $0.05 \mathrm{~mL}$ of a PGZ-NPs suspension of a concentration about $1 \mathrm{mg} / \mathrm{mL}$ of PGZ. After $4 \mathrm{~h}$ the pig was euthanized. Cornea, sclera, aqueous and vitreous humours were processed according to the validated method.

\section{Results}

\subsection{Method Validation}

\subsubsection{Selectivity and Specificity}

The analysis of blank samples showed no interfering signals in chromatograms of the blank extracts. The retention time for PGZ was about $3 \mathrm{~min}$ and there was no any matrix component to interfere in any of the tissues tested. Typical MRM chromatogram of PGZ found in cornea and PGZ standard $(10 \mathrm{ng} / \mathrm{mL})$ are shown in Figure 1. 


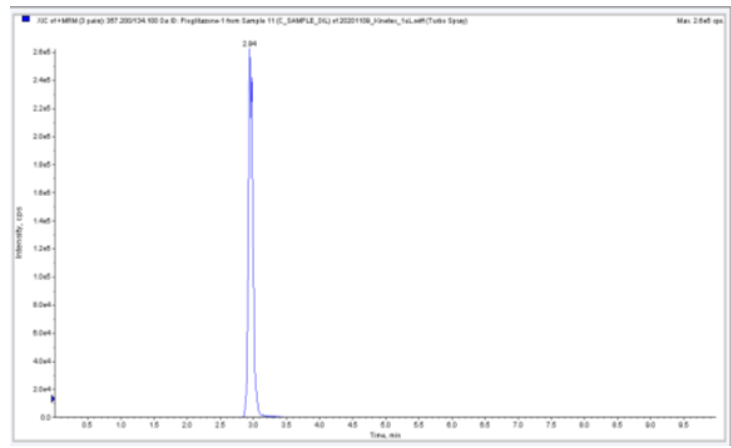

(A)

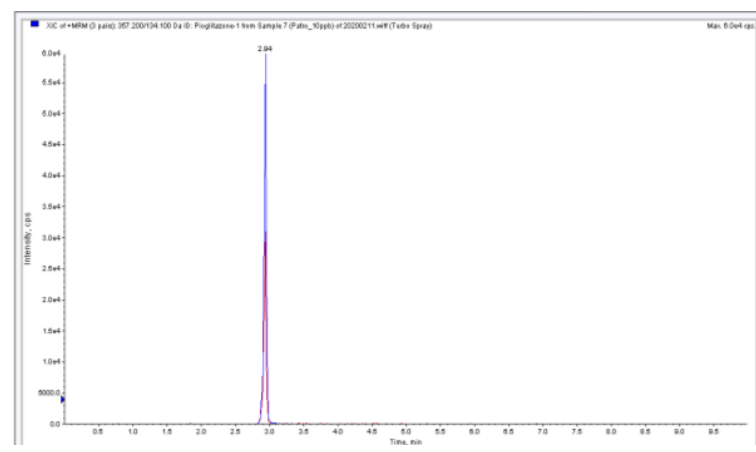

(B)

Figure 1. Typical MRM chromatograms of (A) PGZ in swine cornea treated with PGZ-NPs; (B) PGZ standard $10 \mathrm{ng} / \mathrm{mL}$.

\subsubsection{Matrix Effect}

The matrix components of the tissues did not change the PGZ response with respect to the analyte in a matrix of methanol as the variation found was $<5 \%$. The external calibration method could therefore be used.

\subsubsection{Recovery}

The concentration of the spiked sample extracts was calculated from the PGZ calibration curve (Tables 1-3). Average extraction recoveries for PGZ, $n=3$, were in the range $85-110 \%$ (bias $-15 \%$ to $+10 \%$ ). For all matrices the results are in accordance with the acceptance criteria: CV not exceeding $15 \%$ for precision and bias within $\pm 15 \%$ for accuracy. The method is applicable to PGZ and PGZ-NPs.

Table 1. Absolute recovery (values in mean percentages) of PGZ determined at low, medium and high concentration, and 50-fold diluted sample. Intra-day results $(n=3)$.

\begin{tabular}{cccccc}
\hline $\begin{array}{c}\text { Nominal Concentration } \\
\text { in Extract }\end{array}$ & \multicolumn{5}{c}{ Recovery (\%) } \\
\hline $\mathbf{n g} / \mathbf{m l}$ & Lens & Cornea & Sclera & Aqueous Humour & Vitreous Humour \\
\hline \multirow{2}{*}{10} & $89.0 \pm 1.9^{*}$ & $96.9 \pm 0.5$ & $97.7 \pm 3.3$ & $92.2 \pm 0.4$ & $89.5 \pm 1.6$ \\
& $\mathrm{CV}(\%)=2.1$ & $\mathrm{CV}(\%)=0.5$ & $\mathrm{CV}(\%)=3.4$ & $\mathrm{CV}(\%)=0.4$ & $\mathrm{CV}(\%)=1.7$ \\
\hline \multirow{2}{*}{20} & $85.0 \pm 1.4$ & $100.9 \pm 2.2$ & $98.5 \pm 2.7$ & $91.6 \pm 1.2$ & $89.4 \pm 0.4$ \\
& $\mathrm{CV}(\%)=1.7$ & $\mathrm{CV}(\%)=2.2$ & $\mathrm{CV}(\%)=2.7$ & $\mathrm{CV}(\%)=1.3$ & $\mathrm{CV}(\%)=0.4$ \\
\hline \multirow{2}{*}{100} & $85.2 \pm 0.5$ & $93.9 \pm 3.2$ & $88.4 \pm 2.7$ & $86.4 \pm 1.1$ & $86.7 \pm 1.7$ \\
& $\mathrm{CV}(\%)=0.6$ & $\mathrm{CV}(\%)=3.4$ & $\mathrm{CV}(\%)=3.1$ & $\mathrm{CV}(\%)=1.3$ & $\mathrm{CV}(\%)=1.9$ \\
\hline \multirow{2}{*}{2500} & $109.6 \pm 3.8$ & $85.0 \pm 0.7$ & $88.0 \pm 0.4$ & $97.2 \pm 1.8$ & $99.6 \pm 0.4$ \\
& $\mathrm{CV}(\%)=3.5$ & $\mathrm{CV}(\%)=0.8$ & $\mathrm{CV}(\%)=0.4$ & $\mathrm{CV}(\%)=1.9$ & $\mathrm{CV}(\%)=0.4$ \\
\hline
\end{tabular}

${ }^{*}$ Mean \pm SD

Table 2. Absolute recovery (values in mean percentages) of PGZ determined at low, medium and high concentration. Inter-day accuracy and precision data $(n=9)$.

\begin{tabular}{cccccc}
\hline $\begin{array}{c}\text { Nominal Concentration } \\
\text { in Extract }\end{array}$ & \multicolumn{5}{c}{ Recovery (\%) } \\
\hline $\mathbf{n g} / \mathbf{m l}$ & Lens & Cornea & Sclera & Aqueous Humour & Vitreous Humour \\
\hline \multirow{2}{*}{10} & $93.1 \pm 4.9^{*}$ & $97.8 \pm 1.5$ & $89.7 \pm 7.9$ & $92.3 \pm 8.4$ & $98.3 \pm 6.7$ \\
& $\mathrm{CV}(\%)=5.2$ & $\mathrm{CV}(\%)=1.5$ & $\mathrm{CV}(\%)=8.8$ & $\mathrm{CV}(\%)=9.1$ & $\mathrm{CV}(\%)=6.8$ \\
\hline \multirow{2}{*}{20} & $91.8 \pm 5.3$ & $97.4 \pm 3.1$ & $89.1 \pm 8.2$ & $92.5 \pm 5.7$ & $98.5 \pm 6.9$ \\
& $\mathrm{CV}(\%)=5.8$ & $\mathrm{CV}(\%)=3.2$ & $\mathrm{CV}(\%)=9.2$ & $\mathrm{CV}(\%)=6.2$ & $\mathrm{CV}(\%)=7.0$ \\
\hline \multirow{2}{*}{100} & $87.8 \pm 2.2$ & $93.0 \pm 6.9$ & $85.0 \pm 3.1$ & $87.7 \pm 4.8$ & $92.3 \pm 4.3$ \\
& $\mathrm{CV}(\%)=2.4$ & $\mathrm{CV}(\%)=7.4$ & $\mathrm{CV}(\%)=3.6$ & $\mathrm{CV}(\%)=5.4$ & $\mathrm{CV}(\%)=4.7$ \\
\hline
\end{tabular}

* Mean \pm SD 
Table 3. Intra-day accuracy and precision data $(n=3)$ for tissues spiked with PGZ-NPs: low, medium and high concentration levels, and 50-fold diluted sample.

\begin{tabular}{cccccc}
\hline $\begin{array}{c}\text { Nominal Concentration } \\
\text { in Extract }\end{array}$ & \multicolumn{5}{c}{ Recovery (\%) } \\
\hline $\mathbf{n g} / \mathbf{m l}$ & Lens & Cornea & Sclera & Aqueous Humour & Vitreous Humour \\
\hline \multirow{2}{*}{8.4} & $87.2 \pm 2.3 *$ & $88.3 \pm 0.5$ & $92.0 \pm 3.4$ & $87.4 \pm 3.7$ & $98.4 \pm 6.0$ \\
& $\mathrm{CV}(\%)=2.6$ & $\mathrm{CV}(\%)=0.6$ & $\mathrm{CV}(\%)=3.7$ & $\mathrm{CV}(\%)=4.2$ & $\mathrm{CV}(\%)=6.1$ \\
\hline \multirow{2}{*}{16.8} & $107.7 \pm 3.2$ & $92.1 \pm 1.0$ & $94.9 \pm 2.3$ & $85.2 \pm 1.1$ & $98.1 \pm 1.9$ \\
& $\mathrm{CV}(\%)=3.0$ & $\mathrm{CV}(\%)=1.1$ & $\mathrm{CV}(\%)=2.4$ & $\mathrm{CV}(\%)=1.3$ & $\mathrm{CV}(\%)=2.0$ \\
\hline \multirow{2}{*}{84.2} & $102.8 \pm 2.2$ & $90.2 \pm 1.6$ & $88.5 \pm 1.1$ & $85.3 \pm 0.6$ & $95.2 \pm 2.4$ \\
& $\mathrm{CV}(\%)=2.2$ & $\mathrm{CV}(\%)=1.8$ & $\mathrm{CV}(\%)=1.3$ & $\mathrm{CV}(\%)=0.7$ & $\mathrm{CV}(\%)=2.5$ \\
\hline \multirow{2}{*}{2094} & $109.6 \pm 3.8$ & $85.0 \pm 0.7$ & $88.0 \pm 0.4$ & $99.9 \pm 0.4$ & $110.8 \pm 2.1$ \\
& $\mathrm{CV}(\%)=3.5$ & $\mathrm{CV}(\%)=0.8$ & $\mathrm{CV}(\%)=0.4$ & $\mathrm{CV}(\%)=0.4$ & $\mathrm{CV}(\%)=1.9$ \\
\hline
\end{tabular}

* Mean \pm SD.

\subsubsection{Calibration Curve}

The calibration curve was linear in the PGZ concentration range of $5-100 \mathrm{ng} / \mathrm{mL}$ with correlation coefficients $r^{2}>0.99$. The accuracy found of back-calculated concentration during the different days of analysis was within $91-108 \%$.

\subsubsection{Accuracy and Precision}

Experimental concentrations of spiked samples should not deviate more than $\pm 15 \%$ from their nominal concentrations. Results shown in Tables 1-3 indicate that the intra-day and inter-day precisions given as $\mathrm{CV}(\%)$ do not exceed $5 \%$ and $10 \%$ respectively. Intra-day and inter-day accuracies given by bias (100-Recovery \%) varied between $-15 \%$ for lens and sclera in some levels to $+10 \%$ for lens at the level which should be 50-fold dilute, but no bias was observed with the concentration. The acceptance criteria defined by the EMA and FDA were fulfilled at the assessed concentration levels.

\subsubsection{Sample Dilution}

The dilution integrity of the samples to demonstrate that a sample dilution procedure, when required, will not impact the accuracy and precision of the measured concentration of the analyte, was investigated in all matrices. It was demonstrated that a 50 -fold dilution of a spiked sample can be applied when the concentration of the sample is higher than the upper limit of the calibration curve (Tables 1 and 3).

On the contrary, if the concentration was below the lower limit of the calibration curve, a new calibration curve could be constructed, with minor modifications like the injection volume to get more intensity, because it was found that standards of PGZ of $0.05 \mathrm{ng} / \mathrm{mL}$ provided a good signal. However, according to international guidelines, the result should be confirmed with a partial validation, comprising at least accuracy and precision determination.

\subsubsection{Carry-Over}

Carry-over was assessed during method development and validation and it was observed that it was unavoidable. Methanol was injected at the beginning of the sequence, after the standards calibration curve and following the highest levels of spiked sampels. Nevertheless, the intensity of the carry-over signal was practically constant during the batch sequence and with low variation from one day to another. No concentration effect was observed on the carry-over signal. The carry-over signal in the blank of methanol was found to be between $1 \%$ and $4 \%$ of the analyte response at the limit of quantitation level. The extracts of blank tissues showed the same peak intensity than the blank of methanol. These signal values are in the low range of those accepted in the harmonised guidelines of validation methods, $<20 \%$. Accuracy and precision data confirmed that the presence of carry-over effect did not affect the results. 


\subsubsection{Stability}

Long term (3 months) samples stability at $-20{ }^{\circ} \mathrm{C}$ was confirmed based on the obtained results where the values for accuracy $( \pm 15 \%)$ and precision $(\mathrm{CV}<15 \%)$ were found within the acceptable limits. The data for refrigerated stability obtained from in-injector stability $(24 \mathrm{~h})$ and short-term stability $(8 \mathrm{~h})$ at room temperature, indicated that the variation of the response of the extracts was $<5 \%$.

\subsubsection{Limits of Quantification (LOQ) and Detection (LOD)}

The LOQ is defined as the lowest concentration that can be measured with an intra-day and inter-day precision (expressed as the percentage of the coefficient of variation, CV) that must not exceed $20 \%$ and accuracy (expressed as the percentage of the deviation from nominal concentration, bias) that must be within $\pm 20 \%$. The LOQ was evaluated in three replicates on a single day and on three different days, for all studied matrices and was established as $160 \mu \mathrm{g} / \mathrm{kg}$ for sclera, cornea and lens, and $80 \mu \mathrm{g} / \mathrm{kg}$ for aqueous and vitreous humour $(10 \mathrm{ng} / \mathrm{mL}$ in extract).

The limit of detection (LOD) consists of the lowest concentration whose respective signal can be dependably distinguished from the background level. The LOD was assessed by analysing successive dilutions of the studied matrix samples with known concentrations of PGZ, being defined as the concentration that provides a good peak visualization with the lowest signal-to-noise-ratio $(\mathrm{S} / \mathrm{N})$ possible [21]. PGZ concentrations of $0.05 \mathrm{ng} / \mathrm{mL}$ in tissue extract were injected and the signal was more than twice the carry-over signal for all the examined tissues, indicating that LOD were in the range $0.4-0.8 \mu \mathrm{g} / \mathrm{kg}$.

\subsection{In Vivo Bioavailability Study (Method Application)}

The method herein proposed was used in a pilot study to quantify PGZ in cornea, sclera, aqueous and vitreous humours, after their eye administration in form of nanoparticles. The method was sensitive enough to quantify PGZ in the tissues, demonstrating its applicability. Results presented in Table 4 show that the maximum concentration was found in sclera followed by cornea. Aqueous humour was the tissue were the concentration was lower, but it was into the validated concentration range. These levels found are in accordance with published data [2].

Table 4. Analysis of samples: PGZ found in tissues after PGZ-NPs ocular administration $(\mathrm{n}=2)$.

\begin{tabular}{cccccc}
\hline & \multicolumn{1}{c}{ PGZ in Extract $(\mathbf{n g} / \mathbf{m L})$} & \multicolumn{4}{c}{ PGZ in Tissue as is $\mathbf{( m g} / \mathbf{k g})$} \\
\hline & Average & SD & Average & SD & CV (\%) \\
\hline Sclera & 735.5 & 16.0 & 11.81 & 0.26 & 2.18 \\
Cornea & 153.4 & 2.4 & 4.84 & 0.07 & 1.55 \\
Aqueous humour & 89.8 & 1.9 & 0.74 & 0.02 & 2.08 \\
Vitreous humour & 185.0 & 5.4 & 1.59 & 0.05 & 2.92 \\
\hline
\end{tabular}

\section{Discussion}

Previous studies evaluated the nanoparticles of PLGA-PEG of PGZ as ocular drug carriers [2]. It was demonstrated that the ocular penetration and permeability of the drug was successfully improved. Moreover, this colloidal system presented good ocular tolerance. PGZ was found in eye tissues of treated animals with the method here described. This method was validated in this work to improve the quality and consistency of data found.

The extraction recovery was satisfactory for free pioglitazone and pioglitazone encapsulated in a nanoparticle of PLGA-PEG (recoveries found in the range 85-110\%). The reproducibility of the method obtained by means of the inter-day and intra-day precision was $\mathrm{CV}<10 \%$ and $\mathrm{CV}<5 \%$ respectively. The LOD and LOQ achieved in tissue were in the orders of $0.08 \mu \mathrm{g} / \mathrm{kg}$ and $160 \mu \mathrm{g} / \mathrm{kg}$ respectively. LOD and LOQ in eye humours were in the orders of $0.04 \mu \mathrm{g} / \mathrm{kg}$ and $80 \mu \mathrm{g} / \mathrm{kg}$ respectively. The experimental data agree to guidelines for bioanalytical method validation $[17,18]$. 
PGZ concentrations found in eye tissues after $4 \mathrm{~h}$ of the PGZ-NPs instillation were significant (Table 4) which means that the formulation permeated and remained in the tissues. PGZ accumulated more in sclera than in cornea as it was shown in previous data [2]. This new biodistribution experiment supports previous results and this validated method covers the needed concentration range to study different parts of the eye after treatment with PGZ.

Next step to the development of the PGZ formulation in nanoparticles is the application of spraydrying and freeze-drying as techniques to stabilize and preserve the colloidal system in a dried form. The conditions of drying normally stress the nanoparticles and therefore it must be proven that after reconstituition they keep the initial biopharmaceutical properties. The validated method will be used in future studies in vitro, ex vivo and in vivo of the formulations (eyedrops of semisolid form) for the ocular therapies after the drying proces.

\section{Conclusions}

An accurate, sensitive, selective, reproducible and high throughput HPLC-MS/MS method was developed and fully validated for the quantitative determination of PGZ over a wide concentration range in different eye tissues. This method has the advantage of a simple sample preparation thus reducing assay time. The sensitivity and selectivity achieved for the detection of PGZ with respect of HPLC-UV makes it suitable for analysing very low levels of concentration in complex biological matrices. Moreover, HPLC-MS/MS allows the unambiguous identification of PGZ. Published data show that HPLC/MS has been used for PGZ quantitation in liquid biological samples (urine, plasma, serum) [22,23] but not in biological tissues. The sensitivity was slightly improved compared to data found in the literature [22].

The method can be easily applied to in vivo and ex vivo biodistribution studies related to the ocular administration of PGZ in a nanoparticle carrier and opens the applicability to other types of biological matrices for preclinical or clinical use.

Author Contributions: E.M.-C., M.S.-A. and A.C.C.-C. conceived and designed the experiments; E.M.-C. performed the experiments; E.M.-C. and I.C.-R. analyzed the data; E.M.-C. wrote the paper. All authors have read and agreed to the published version of the manuscript.

Acknowledgments: The authors would like to acknowledge HPLC/MS Technicians Alberto Adeva-Antón and Olga Jáuregui-Pallarés of Separative Techniques Unit of the Scientific and Technological Centres of the University of Barcelona (CCiTUB) for help with the HPLC/MS management. The authors would like to thank Lídia Gómez-Segura and Álvaro Gimeno-Sandig of the Bellvitge Hospital of Barcelone for her assistance in the management of the animals used in the experiments.

Conflicts of Interest: The authors declare no conflict of interest. The founding sponsors had no role in the design of the study; in the collection, analyses, or interpretation of data; in the writing of the manuscript, and in the decision to publish the results.

\section{Abbreviations}

The following abbreviations were used in this manuscript:

$\begin{array}{ll}\text { HPLC } & \text { High Performance Liquid Chromatography } \\ \text { MS } & \text { Mass Spectrometry } \\ \text { NPs } & \text { Nanoparticles } \\ \text { PEG } & \text { Polyethylene glycol } \\ \text { PGZ } & \text { Pioglitazone } \\ \text { PLGA } & \text { Polylactic-co.glycolyc acid } \\ \text { PPAR } \gamma & \text { Peroxisome proliferator-activated receptor } \\ \text { PVA } & \text { Poly (vinyl alcohol) }\end{array}$




\section{References}

1. Yamamoto, A.; Kakuta, H.; Miyachi, H.; Sugimoto, Y. Involvement of the Retinoid X Receptor Ligand in the Anti-Inflammatory Effect Induced by Peroxisome Proliferator-Activated Receptor $\gamma$ Agonist In Vivo. Ppar Res. 2011, 840194, doi:10.1155/2011/840194.

2. Silva-Abreu, M.; Calpena, A.C.; Espina, M.; Silva, A.M.; Gimeno, A.; Egea, M.A.; García, M.L. Optimization, biopharmaceutical profile and therapeutic efficacy of pioglitazone-loaded PLGA-PEG nanospheres as a novel strategy for ocular inflammatory disorders. Pharm. Res. 2018, 35, 11.

3. Okunuki, Y.; Usui, Y.; Nakagawa, H.; Tajima, K.; Matsuda, R.; Ueda, S.; Hattori, T.; Kezuka, T.; Goto, H. Peroxisome proliferator-activated receptor-g agonist pioglitazone suppresses experimental autoimmune uveitis. Exp. Eye Res. 2013, 116, 291-297.

4. Uchiyama, M.; Shimizu, A.; Masuda, Y.; Nagasaka, S.; Fukuda, Y.; Takahashi, H. An ophthalmic solution of a peroxisome proliferator-activated receptor gamma agonist prevents corneal inflammation in a rat alkali burn model. Mol. Vis. 2013, 19, 2135-2150.

5. Silva-Abreu, M.; Espinoza, L.C.; Rodríguez-Lagunas, M.J.; Fábrega, M.J.; Espina, M.; García, M.L.; Calpena, A.C. Human skin permeation studies with PPAR $\gamma$ agonist to improve its permeability and efficacy in inflammatory processes. Int. J. Mol. Sci. 2017, 18, 2548.

6. Kanemaru, M.; Asai, J.; Jo, J.; Arita, T.; Kawai-Ohnishi, M.; Tsutsumi, M.; Wada, M.; Tabata, Y.; Katoh, N. Nanoparticle-mediated local delivery of pioglitazone attenuates bleomycin-induced skin fibrosis. J. Dermatol. Sci. 2019, 93, 41-49.

7. Matoba, T.; Koga, J.; Nakano, K.; Egashira, K.; Tsutsui, H. Nanoparticle-mediated drug delivery system for atherosclerotic cardiovascular disease. J. Cardiol. 2017, 70, 206-211.

8. Tokutome, M.; Matoba, T.; Nakano, Y.; Okahara, A.; Fujiwara, M.; Koga, J.; Nakano, K.; Tsutsui, H.; Egashira, K. Peroxisome proliferator-activated receptor-gamma targeting nanomedicine promotes cardiac healing after acute myocardial infarction by skewing monocyte/macrophage polarization in preclinical animal model. Cardiovasc. Res. 2019, 115, 419-431, doi:10.1093/cvr/cvy200.

9. Jojo, G.M.; Kuppusamy, G.; De, A.; Karri, V.N.R. Formulation and optimization of intranasal nanolipid carriers of pioglitazone for the repurposing in Alzheimer's disease using Box-Behnken design. Drug Dev. Ind. Pharm. 2019, 45, 1061-1072, doi:10.1080/03639045.2019.1593439.

10. Silva-Abreu, M.; Gonzalez-Pizarro, R.; Espinoza, L.C.; Rodríguez-Lagunas, M.J.; Espina, M.; García, M.L.; Calpena, A.C. Thiazolidinedione as an alternative to facilitate oral administration in geriatric patients with Alzheimer's disease. Eur. J. Pharm. Sci. 2019, 129, 173-180.

11. Bachu, R.D.; Chowdhury, P.; Al-Saedi, Z.H.F.; Karla, P.K.; Boddu, S.H.S. Ocular Drug Delivery Barriers. Role of Nanocarriers in the Treatment of Anterior Segment Ocular Diseases. Pharmaceutics 2018, 10, 28, doi:10.3390/pharmaceutics10010028.

12. Ghafoorianfar, S.; Ghorani-Azam, A.; Mohajeri, S.A.; Farzin, D. Efficiency of nanoparticles for treatment of ocular infections: Systematic literature review. J. Drug Deliv. Sci. Technol. 2020, 57, 101765.

13. Cañadas, C.; Alvarado, H.; Calpena, A.C.; Silva, A.M.; Souto, E.B.; García, M.L.; Abrego, G. In vitro, ex vivo and in vivo characterization of PLGA nanoparticles loading pranoprofen for ocular administration. Int. J. Pharm. 2016, 511, 719-727.

14. Luis de Redín, I.; Boiero, C.; Martínez-Ohárriz, M.C.; Agüeros, M.; Ramos, R.; Peñuelas, I.; Allemandi, D.; Llabot, J.M.; Irache, J.M. Human serum albumin nanoparticles for ocular delivery of bevacizumab. Int. J. Pharm. 2018, 541, 214-223.

15. Silva, B.; Marto, J.; São Braz, B.; Delgado, E.; Almeida, J.A.; Gonçalves, L. New nanoparticles for topical ocular delivery of erythropoietin. Int. J. Pharm. 2020, 576, 119020.

16. Danhier, F.; Ansorena, E.; Silva, J.M.; Coco, R.; Le Breton, A.; Préat, V. PLGA-based nanoparticles: An overview of biomedical applications. J. Control. Release 2012, 161, 505-522.

17. European Medicines Agency. EMA/CHMP/ICH/172948/2019. ICH Guideline M10 on Bioanalytical Method Validation; European Medicines Agency: Amsterdam, The Netherlands, 2019.

18. U.S. Food and Drug Administration. Bioanalytical Method Validation, Guidance for Industry; U.S. Food and Drug Administration: Silver Spring, MD, USA, 2018.

19. Fessi, H.; Puisieux, F.; Devissaguet, J.P.; Ammoury, N.; Benita, S. Nanocapsule formation by interfacial polymer deposition following solvent displacement. Int. J. Pharm. 1989, 55, R1-R4. 
20. Almeida, A.M.; Castel-Branco, M.M.; Falcao, A.C. Linear regression for calibration lines revisited: Weighting schemes for bioanalytical methods. J. Chromatogr. B 2002, 774, 215-222, doi:10.1016/S15700232(02)00244-1.

21. ICH. Validation of Analytical Procedures: Text and Methodology, Q2(R1). 2005. Available online: https://www.ich.org.

22. Satheeshkumar, N.; Shantikumar, S.; Srinivas, R. Pioglitazone: A review of analytical methods. J. Pharm. Anal. 2014, 4, 295-302.

23. Sengupta, P.; Chatterjee, B.; Kumar-Mandal, U.; Gorain, B.; Kumar-Pal, T. Development and validation of a high throughput LC-MS/MS method for simultaneous quantitation of pioglitazone and telmisartan in rat plasma and its application to a pharmacokinetic study. J. Pharm. Anal. 2017, 7, 381-387.

Publisher's Note: MDPI stays neutral with regard to jurisdictional claims in published maps and institutional affiliations.

(C) 2020 by the authors. Submitted for possible open access publication under the terms and conditions of the Creative Commons Attribution (CC BY) license (http://creativecommons.org/licenses/by/4.0/). 